\title{
The impact of pre and perinatal lifestyle factors on child long term health and social outcomes: a systematic review
}

\author{
Kerry Bell ${ }^{1 *}$ (D), Belen Corbacho', Sarah Ronaldson', Gerry Richardson², David Torgerson', Michael Robling ${ }^{3}$ \\ and on behalf of the Building Blocks trial group
}

\begin{abstract}
To understand the full extent of the impact of a trial, it is important to consider the long-term consequences of outcomes beyond the trial follow-up period, especially for early year's interventions. A systematic review of the literature associated with the long-term consequences of four key outcomes from the Building Blocks trial, specifically, low birth weight, smoking during pregnancy, interval to subsequent pregnancy and A\&E attendance or inpatient admission was conducted. These factors were guided by the funders, the Department of Health, as being of particular interest in the UK context. Relevant studies were identified from a number of sources including large databases, reference checking and citation searching. The search yielded 3665 papers, 43 of which were considered appropriate for inclusion. Of these, 29 were relating to smoking during pregnancy, 13 to low birth weight, 0 to A\&E attendances during early childhood and 1 to short ( $<2$ years) interval to subsequent pregnancy. Consistent associations were found between maternal smoking during pregnancy and the effects this has on children's health, educational attainment and likelihood of engaging in problem behaviour and criminal activity in later life. Low birth weight was also found to impact on children's long-term health and cognitive development. Subsequent pregnancies within two years of the previous birth were linked with increased likelihood of pre-term birth and neonatal death. Only minimal evidence was identified regarding the consequences of a short interval to second pregnancy and of child A\&E and outpatient attendances. Given that these outcomes have been identified by the UK Department of Health as of particular interest for UK benefit, investment of research in these areas is recommended to establish a clearer picture of both short and long-term consequences.
\end{abstract}

Keywords: Home visitation, Birth weight, Smoking, Pregnancy, Child outcomes, Education, Health

\section{Review}

A key short coming within many randomised controlled trials (RCTs) is their relatively short term follow-up. This is a particular problem for early interventions aimed at pregnant women or young children where we might expect some major impacts on children's health and welfare to only become evident some years after an intervention. Consequently, many economic evaluations based on RCT data undertake modelling exercises to assess the cost effectiveness of an intervention making assumptions about long term treatment effects. A key

\footnotetext{
* Correspondence: Kerry.Bell@york.ac.uk

${ }^{1}$ York Trials Unit, Department of Health Sciences, University of York, ARRC

Building, York YO10 5DD, UK

Full list of author information is available at the end of the article
}

issue underpinning such modelling is whether or not proximal outcomes observed in a RCT, and which are often proxy measures, are causally linked to more distal outcomes among children at a later age. For instance, we can be pretty confident that cessation of smoking among pregnant women (a proximal and proxy outcome) will be linked to a future reduction in cancer among the mothers and increases in birthweight among babies. However, there is a greater uncertainty as to whether close mother child bonding will lead to better outcomes in terms of educational achievement lower rates of delinquency and overall increases in future wellbeing.

Although longitudinal outcomes can carry substantial weight in decisions of cost-effectiveness, randomised controlled trials are often limited in their ability to measure 
outcomes over a longer time frame due to feasibility and funding restraints [1]. In these situations, extrapolation modelling can provide decision makers with estimates of the potential long-term consequences associated with the outcomes of a trial by linking information from the wider literature to trial outcome data. The purpose of this being to provide decision makers with a more complete picture of the costs and outcomes of the intervention than the trial alone would do. This type of evidence synthesis and decision modelling are a central process of Health Technology Assessment (HTA), and represent a crucial role in the NICE appraisal process [2].

Due to the potential influence on long-term development, interventions in childhood are particularly linked to long-term consequences both in terms of future benefits and future cost-savings [3-5]. Recognising the importance of linking the outcomes of childhood interventions to long-term developmental trajectories, large scale extrapolation models have been developed both in the United States (US) by the Washington State Institute for Public Policy (WSIPP) [6] and in the United Kingdom (UK) by the Social Research Unit (SRU) [7]. The present work formed part of a comprehensive economic evaluation of Building Blocks, a randomised controlled trial investigating the effectiveness and cost-effectiveness of the provision to first-time teenage mothers of the Family Nurse Partnership (FNP) programme on improving specified infant and maternal outcomes [8]. The trial provided comprehensive data for up to 24 months after birth in terms of the effect on costs and outcomes. However, given that childhood interventions often deliver effects beyond the exploratory period, in this case approximately 30 months, an extrapolation exercise was planned to identify the potential wider and longer-term consequences associated with modifying the primary outcomes of the trial. Existing models such as those constructed by WSIPP and SRU which were designed to predict the potential long-term impact of competing investment options for child wellbeing, as well as the costs and economic returns of interventions [6], use educational attainment and problem behaviour and criminal activity as a basis of their models hence these, as well as health, were considered as the most appropriate outcomes on which to base the Building Blocks extrapolation exercise.

The present review examines the literature associated with the long-term consequences of four key outcome measures from the Building Blocks trial. In commissioning the trial, the Department of Health Policy Research Programme that funded the trial specified inclusion of prenatal tobacco use, childhood injuries requiring emergency department attendance or admission, and interbirth interval as primary outcome measures that were considered on the basis of previous trials to be modifiable by FNP. Having being recommended to the funders by an advisory committee including representatives of the programme, birthweight was also specified as a primary outcome as a policy-relevant and readily measurable outcome that was applicable to all trial participants.

Specifically, the review aimed to identify relevant longitudinal studies relating to the longer term effects of:

- Maternal smoking during pregnancy on the child.

- Infant low birth weight.

- Short-interval to subsequent pregnancy (defined as less than two years).

- Childhood A\&E attendances and inpatient admissions.

\section{Methods}

\section{Search strategy}

The databases MEDLINE and MEDLINE In Process \& Other Non-Indexed Citations (Ovid), British Education Index (ProQuest), Criminal Justice Abstracts (EBSCO), ERIC (ProQuest), PsycINFO (Ovid), Social Policy and Practice (Ovid) and Social Science Citation Index (Web of Knowledge), covering literature published to 2012 (A\&E attendances to 2013) were searched using a prespecified search strategy. The observational study design filter created by SIGN was used and adapted for these searches [9]. In addition to searching these databases, reference checking and citation searching from identified papers was also carried out.

Potentially relevant articles were retrieved and saved in an EndNote library. The search strategy was restricted to include only studies conducted in the four UK constituent countries (England, Scotland, Wales and Northern Ireland). These studies were then assessed for potential inclusion in the review based on a strict set of inclusion and exclusion criteria.

\section{Inclusion and exclusion criteria}

All longitudinal prospective or retrospective design, relating to the primary trial outcomes (birth weight, prenatal tobacco use, emergency attendances and inpatient admissions, and second pregnancy within two years of first birth), measuring child health/well-being/criminality/ education were considered. Due to time restraints for the delivery of the review within the context of the wider Building Blocks trial, and to ensure generalisability to a UK health context, only studies set within the UK were included.

Studies were excluded if the outcome measure of interest was not being investigated as the exposure variable. Study outcomes were not limited by time, i.e. studies could measure outcomes at later points in childhood, adolescence and adulthood. 


\section{Assessment of studies}

Study selection took a step-wise approach. Article titles and, where available, abstracts were screened to determine whether they fulfilled eligibility criteria. Articles not immediately meeting the inclusion criteria were rejected and the reasons for exclusion recorded. Where abstracts were unavailable, full papers were retrieved for consideration. Papers meeting the full inclusion criteria were retrieved for detailed assessment. The first 10\% of citations were screened independently by both the primary reviewer and a secondary reviewer to minimise the risk of bias or errors. Any disagreements were resolved via discussion between the two reviewers. The inclusion strategy was then definitively established and the primary reviewer completed the remaining $90 \%$ of the papers. A flow chart showing the number of studies remaining at each stage was used to document this selection process (Fig. 1).

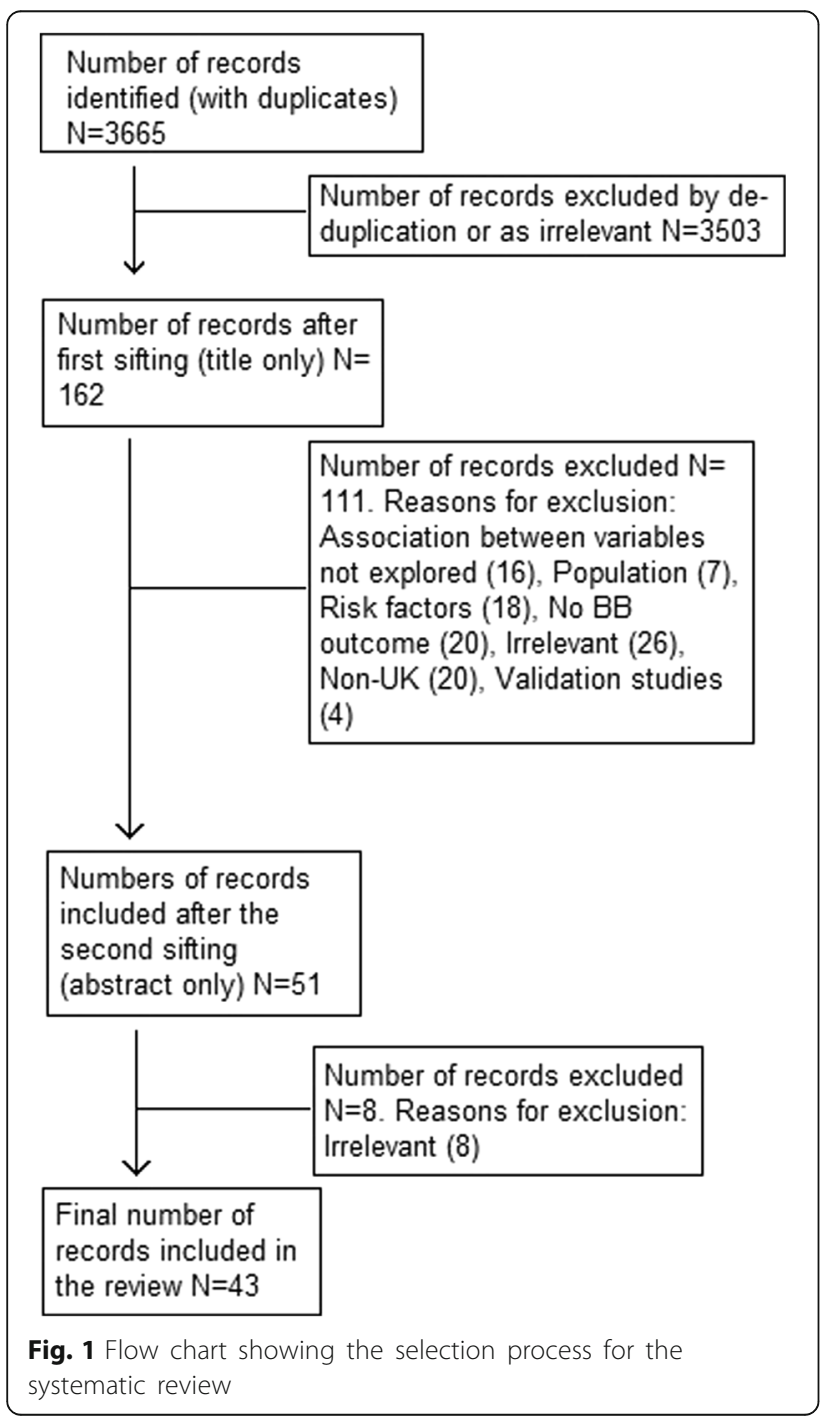

Information on study design, participant characteristics, outcomes, length of follow-up, method of analysis and main findings were extracted.

\section{Quality assessment}

Critical appraisal of identified studies was undertaken with the aid of a known checklist. Although several tools exist, no single tool has been adopted universally to assess quality in non-randomised studies [10]. The existing tools have been systematically reviewed [11], resulting in six tools being identified as useful for quality assessment, though all of which requiring a level of adjustment depending on the research questions. For the present review, relevant articles were evaluated using an adapted version of the Effective Public Health Practice Project (EPHPP) 'Quality Assessment Tool for Quantitative Studies' [12], as identified as a useful tool in the systematic review. This tool considers the appropriateness of the study design to the research question, risk of bias, choice of outcome measure, analytical methods, quality of reporting, quality of the intervention and generalisability.

\section{Data analysis}

A high degree of heterogeneity was identified between the studies meeting the inclusion criteria for the review in terms of study type, sampling and methods used. The results are discussed through means of a narrative synthesis, which highlights the potential long-term benefits that may arise from improvements in these early outcomes. The results are summarised according to the outcome measure assessed.

\section{Results}

The search identified a total of 3665 records of which 3503 were excluded on the basis of title and abstract, leaving a total of 162 for retrieval and full study assessment. Of these, 43 records were deemed suitable, fulfilling the inclusion criteria for the review.

Of the 43 studies retrieved 29 concerned smoking related outcomes, 13 concerned outcomes associated with low birth weight and 1 discussed the outcomes associated with short inter-pregnancy interval.

As per the inclusion criteria, all studies were conducted within a UK context, though one study included comparative data from the Czech Republic [13]. Studies comprised varying sample sizes and examined a vast range of outcomes. The majority of the studies were prospective longitudinal cohort studies $(n=33)$, though 10 retrospective/case-control studies also met the inclusion criteria.

The included studies were largely of moderate or high quality, though two studies did not meet the minimum criteria outlined in the quality checklist and thus were deemed low quality. 


\section{Maternal smoking and child outcomes Health}

Maternal smoking during pregnancy was linked to a wide range of both childhood and adulthood health outcomes. Table 1 summarises the findings.

Of five studies exploring the association between prenatal exposure to maternal smoking and incidence of childhood cancer, only one reported significantly elevated odds of development [14]. This study was unique in the sense that it analysed the impact based on all types of childhood cancer, in contrast to the other four which focused on only specific types of cancer. Whilst this aspect of the design may be beneficial to assessing the relationship between smoking exposure and the broad spectrum of cancer diseases, the study was largely hindered by a very small case-control based sample size $(n=132)$, matched on only a narrow range of potentially confounding variables. Given the limitations of this design and the high correlation between the other four studies identified, there appears to be little evidence in a UK setting supporting a link between maternal smoking and subsequent incidence of childhood cancers.

Wheeze and asthma related health problems were consistently associated with smoking during pregnancy [13, 15-17], with all four studies investigating this outcome reporting a significant association (OR 1.3-4.43). All four studies were deemed of moderate to high quality, employing large, generalizable samples and accounting for a good range of covariates in statistical models.

The most prominent health concern associated with maternal prenatal smoking was weight related problems, which were noted not only in childhood but also throughout adulthood. Eight studies engaged this as an outcome measure, two of which looked at child outcomes $[18,19]$ with the remaining six focusing on adult outcomes [20-25]. Children of prenatal smokers were between 1.23 and 1.49 times more likely than children of non-smokers to develop childhood obesity, according to the number of cigarettes mothers smoked per day $[18,19]$. The probability of developing obesity in adulthood was slightly more pronounced with similar increases in the likelihood being found across the 3 studies using this outcome (OR 1.4-2.27) [20-22]. Additionally children of prenatal smokers were also more likely to experience poor appetite control in adulthood (likely to facilitate obesity) [25], and may be more likely to develop diabetes [23], though this specific association is questionable and inconsistent across studies [24]. Given the vast health related costs associated with weight related problems, this finding presents a clear example of how a reduction in maternal prenatal smoking could be vastly beneficial and cost saving over time.

Links were also identified with Sudden Infant Death Syndrome (SIDS) [26], orofacial abnormalities such as cleft palate [27], and neurological functioning assessed through measures of motor control [28], emphasising the breadth of potential health benefits that could be achieved by reducing maternal smoking during pregnancy.

\section{Cognitive development and educational attainment}

Table 2 presents the findings relating to maternal smoking and child cognitive and educational outcomes. No association was identified between maternal prenatal smoking and children's academic attainment measured through test-scores [29]. However, two studies did report a significant association with problematic behaviour in school aged children [30, 31], which may affect learning. Increases in the likelihood of children engaging in problematic behaviour ranged from 1.17 times more likely to 1.80 times more likely depending on the type of behaviour measured and the quantity of cigarettes the mother had smoked during pregnancy. However, both of these studies lacked a rigorous selection of potential confounders in the analysis. Additionally, the final study employing this outcome reported no significant association after covariates had been adjusted for [32].

\section{Problem behaviour and criminal activity}

As shown in Table 3, three studies reporting on problem behaviour and criminal activity or anti-social behaviour measures during late childhood through to adulthood met the criteria for inclusion. Although no significant association was found between maternal smoking and child smoking and alcohol use at age 10 (Macleod et al., 2008) and child antisocial behaviour at age 16 [33], children of prenatal smokers were found to be more likely to report convictions for criminal activity in adulthood (OR 1.4-1.8), with female children being more affected than male children [34]. Although these findings are drawn from only 1 study, this was deemed high quality research boasting a vast sample size $(n=16,401)$, where a diverse range of covariates were included in statistical analyses, including maternal depression, a known risk factor for problematic behaviour and criminal activity in children [35-37].

\section{Low infant birth weight and child outcomes Health}

Table 4 presents the findings relating to low birth weight and health. Data were extracted from 9 studies exploring the effects of low birth weight on future health outcomes. Three of these were prospective cohort studies representative of the entire British population [38-40], four longitudinal [41-44] and two cross- sectional $[45,46]$ studies.

In childhood, having a low birth weight $(<2.5 \mathrm{~kg})$ was associated with an increased likelihood of asthma and 
wheeze disorders (OR 1.57, 95\% CI 1.1-2.25) [38] and moreover was identified as a factor that is often associated with preventable childhood death occurring before the age of five [46].

Preventing low birth weight may be important for some factors affecting cardio vascular health in adulthood. For instance, for every additional kilogram in birth weight, a significant decrease was found in blood pressure, both in childhood (age 4) and throughout adulthood (to age 71) [40]. Similarly increasing birth weight to a normal level was associated with lower cholesterol levels in adulthood [45] though no significant effects on fibrinogen levels in adulthood [41] or diabetes in childhood [43] were noted. Improving birth weight could thus potentially bring about a substantial potential benefit given the associations between high blood pressure and various health conditions such as hypertension and stroke.

Psychological health in adulthood may be affected by low birth weight, with both men and women being more likely to report a history of depression [39], and being of greater risk of suicide [42]. Having a first child with a low birth weight was identified as a significant risk factor for complications in subsequent pregnancies, most notably stillbirth (HR 2.32, 95\% CI 1.82-2.96, $p<.001)$ [44].

\section{Cognitive development and educational attainment}

Table 5 presents the findings relating to low birth weight and development and attainment outcomes. Data were extracted from 4 studies examining the effects of low infant birth weight on cognitive development and wellbeing. Low birth weight may increase the likelihood of requiring special educational support in childhood, with teachers being more likely to recommend specialist support at age 16 for children who had a low birth weight compared to children that fell within the normal range (4.9\% vs $2.3 \%)$ [47]. This study also showed that low birth weight children were less likely to be in the top performing 15th percentile of their class $(13 \%$ vs $20 \%$, $p<0.01)$ possibly reflecting differences in cognitive abilities. Indeed, one large scale retrospective cohort study reported that children of low birth weight were almost 2.5 times more likely to experience intellectual impairments (OR 2.67 CI 2.41-2.96), sensory problems (OR 2.85, 95\% CI 2.04-3.99) and motor problems (OR 2.47, 95\% CI 1.82-3.37) [48].

In adulthood, low birth weight children were found to be less likely to have professional or managerial jobs at age $26(8.7 \%$ vs $16.4 \%, p<0.01)$ and yield significantly lower levels of weekly income, earning on average $£ 21$ per week less than children of normal birth weight $(p<.01)$ [47].

\section{Short-duration to second pregnancy}

Table 6 presents the findings relating to a short interval to second pregnancy.

Only 1 study of moderate quality was identified pertaining to the impact of a short duration to a second pregnancy [49]. This study employed a retrospective cohort of 89,194 families in Scotland and focused on the outcomes for the second child. A short inter-pregnancy interval of 6 months or less was identified as an independent risk factor for both extremely preterm birth occurring at 24-32 weeks (OR 2.2, 95\% CI 1.4-3.6) and moderately preterm birth occurring at 33-36 weeks (OR 1.6, 95\% CI 1.3-2.0). More severely, a short interpregnancy interval was also associated with an increased likelihood of neonatal death (unrelated to a congenital abnormality) (OR 3.6, 95\% CI 1.2-10.7).

\section{A\&E and outpatient attendances in early childhood and child outcomes}

No papers were identified examining the long-term consequences of $A \& E$ and outpatient attendances (for any reason) for early childhood.

\section{Discussion and conclusion}

This review aimed to identify, evaluate and summarise all relevant existing studies set within a UK context that have explored the association between the primary outcomes of the Building Blocks trial and longer term effects for the children in terms of health, education, employment and criminality with the view of informing an extrapolation exercise. A broad search was employed which aimed to identify studies relating to maternal smoking during pregnancy, effects of low birth weight, effects of short interval to subsequent pregnancy $(<$ 2 years) and to identify relevant longitudinal studies relating to childhood A\&E attendances and inpatient admissions.

After undertaking a rigorous search of the literature guided by pre-defined inclusion and exclusion criteria, 43 studies were identified for inclusion in the review. Of the four trial outcomes of interest, maternal smoking during pregnancy and the effects this has on children's health and general development yielded the most results. This accounted for 28 of the included studies. Studies centring on outcomes relating to low birth weight were the second most prevalent (14 studies), whereas studies relating to the final two trial outcomes were prominently absent with only one study discussing short interval to subsequent pregnancy and no studies addressing the long-term outcomes associated with early A\&E attendance and outpatient attendances, in particular for child injuries and ingestions. This reflects a gap in the UKbased literature within this subject area. 


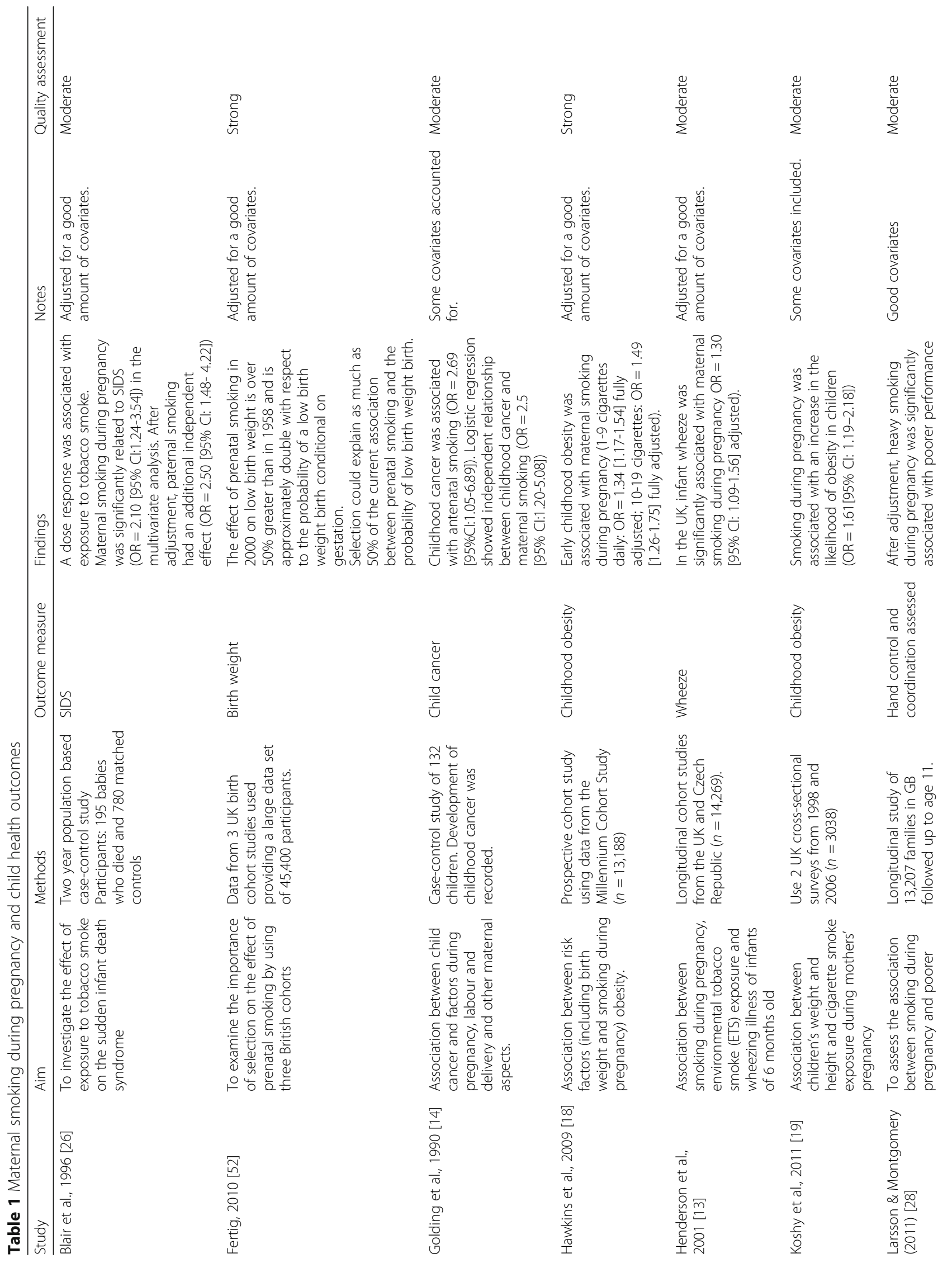



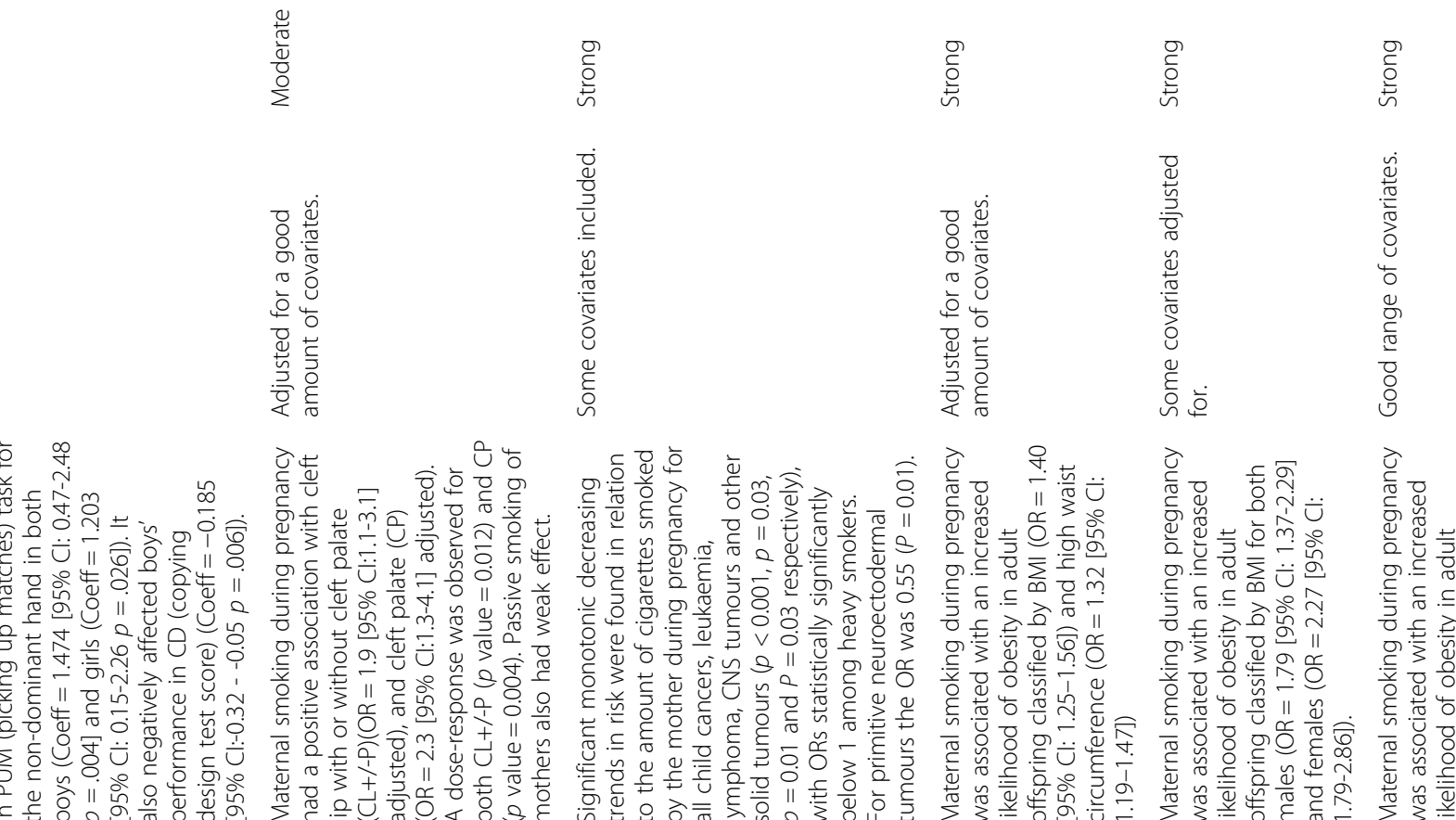
人 d

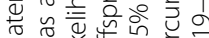

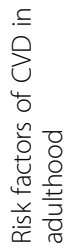

ते
$\frac{1}{0}$
$\frac{0}{0}$
$\frac{0}{8}$
0
$\frac{1}{1}$
$\frac{7}{5}$
$\frac{0}{4}$

$\frac{7}{4}$
0
0
0
0
0
0
$\frac{0}{ \pm}$
$\frac{5}{0}$
$\frac{0}{4}$
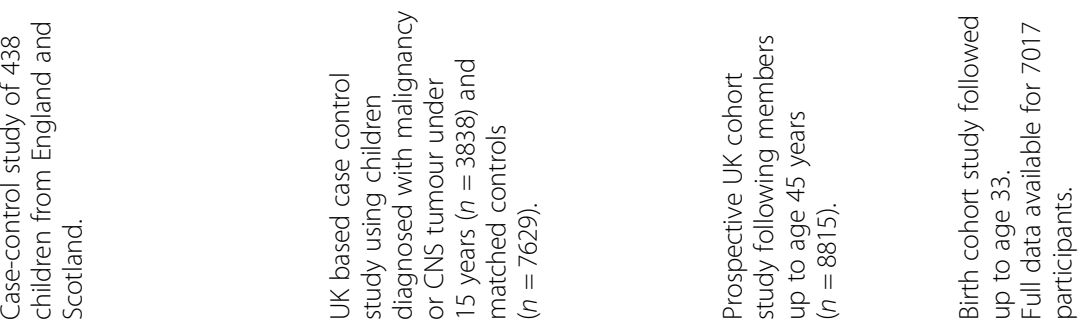

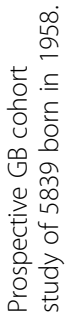
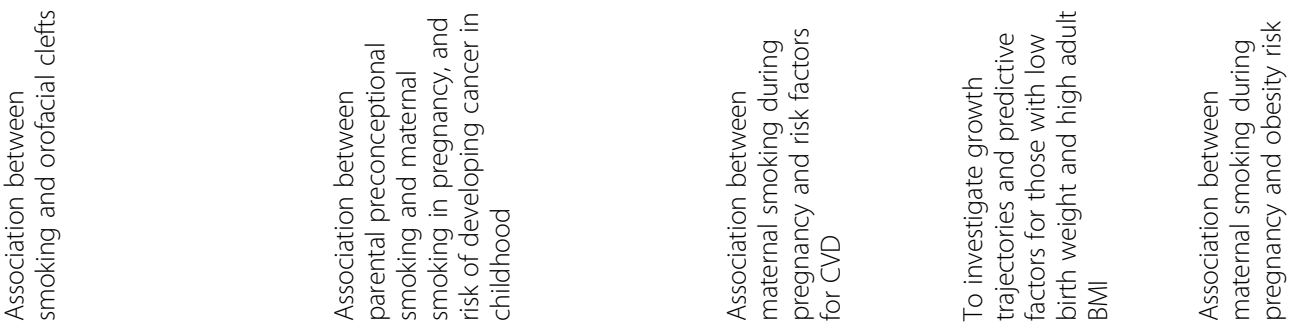

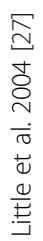

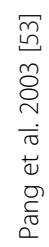

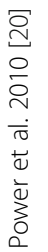

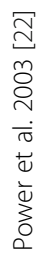

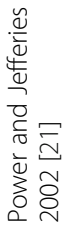




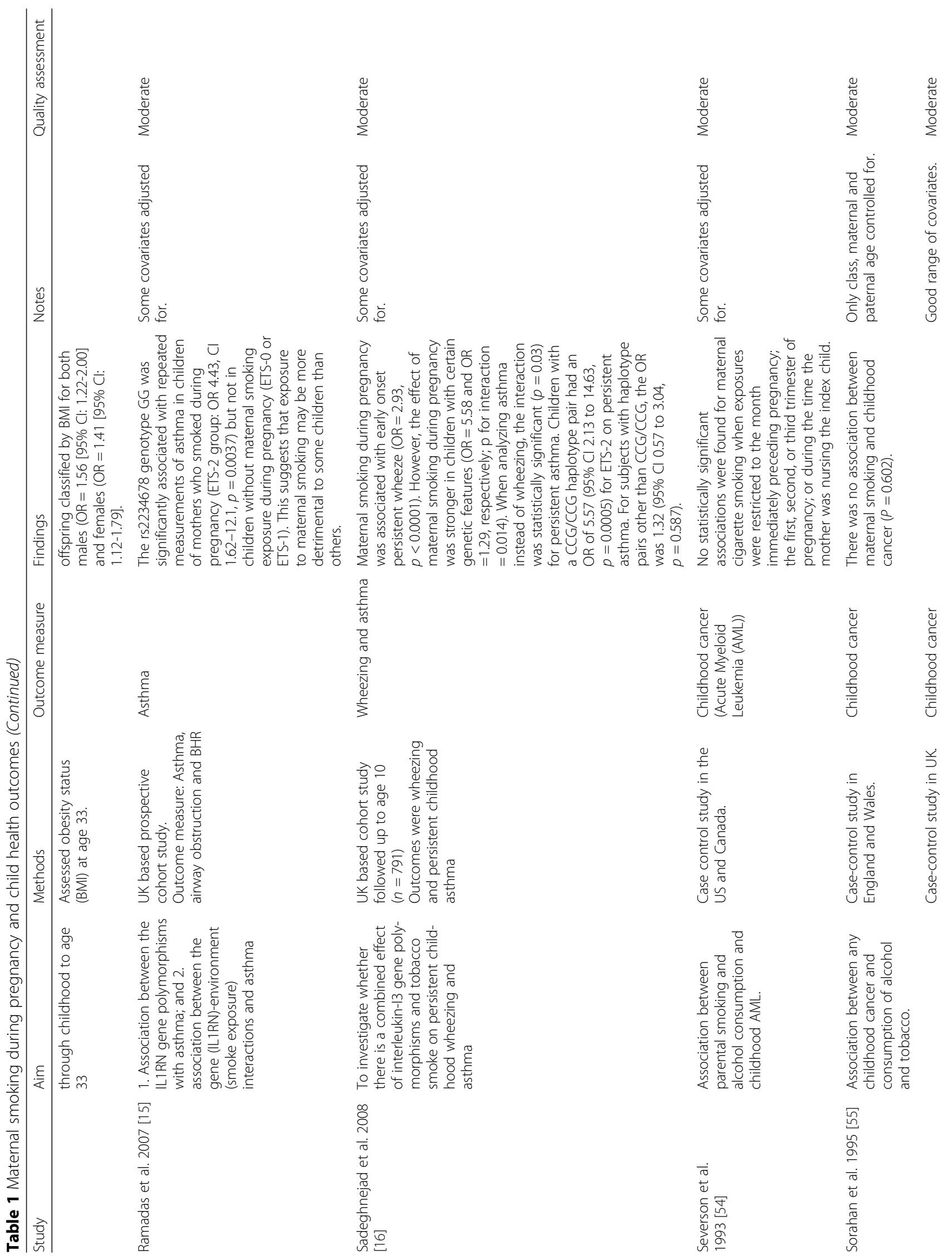




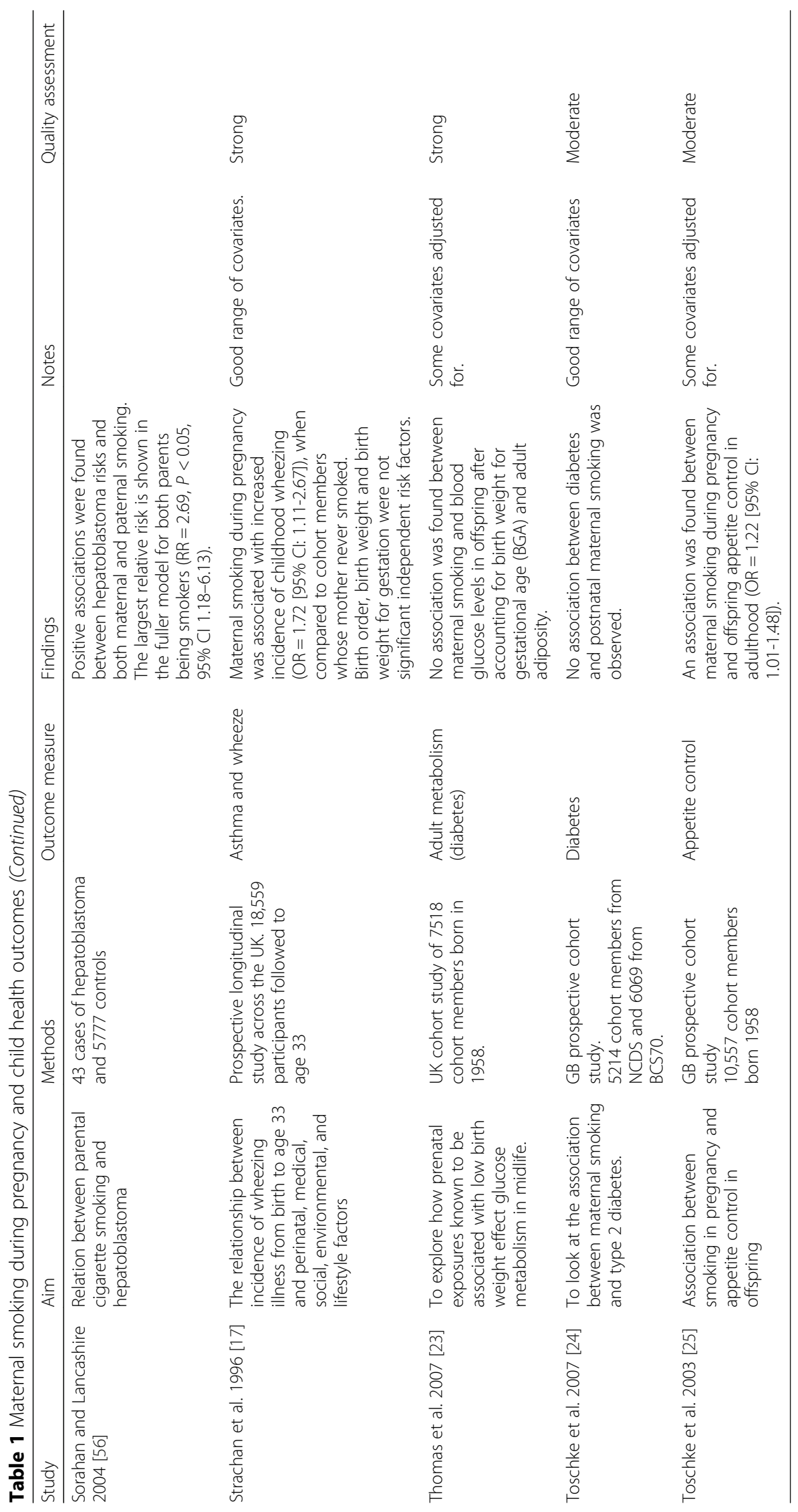




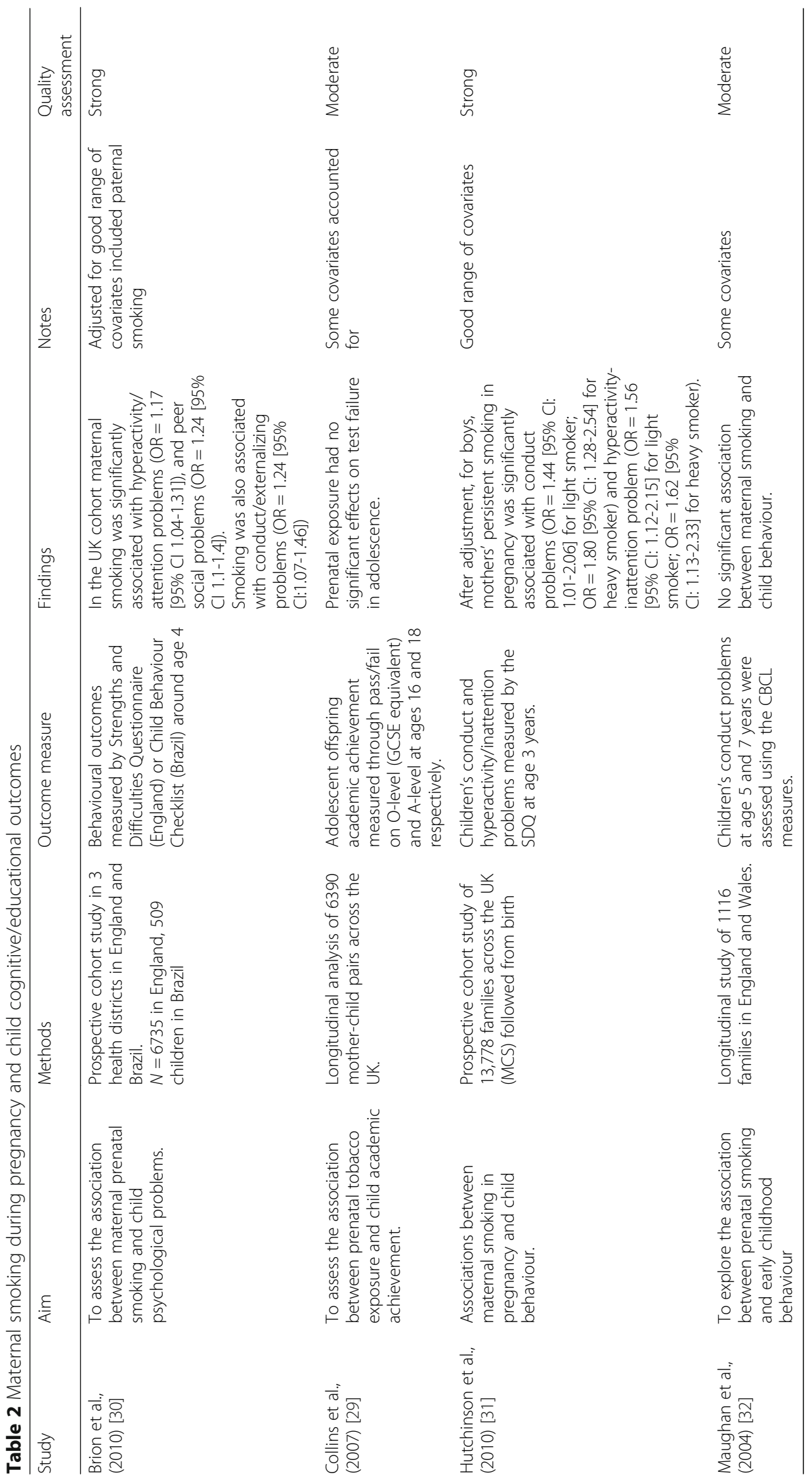




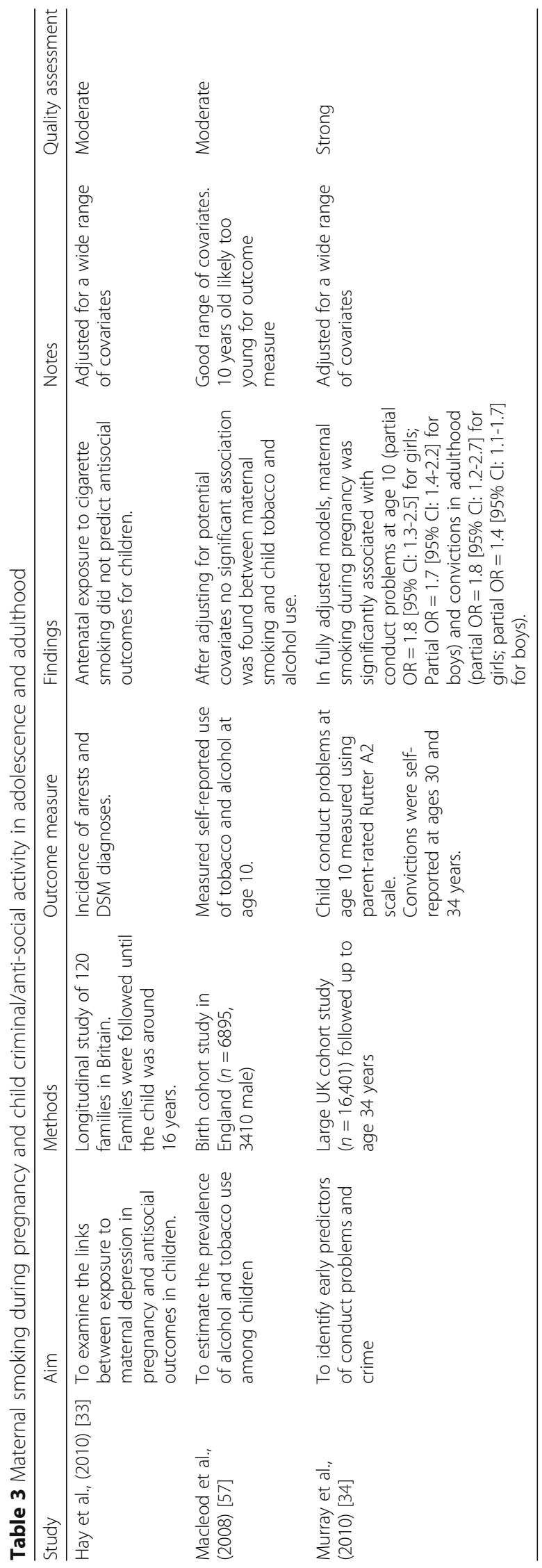




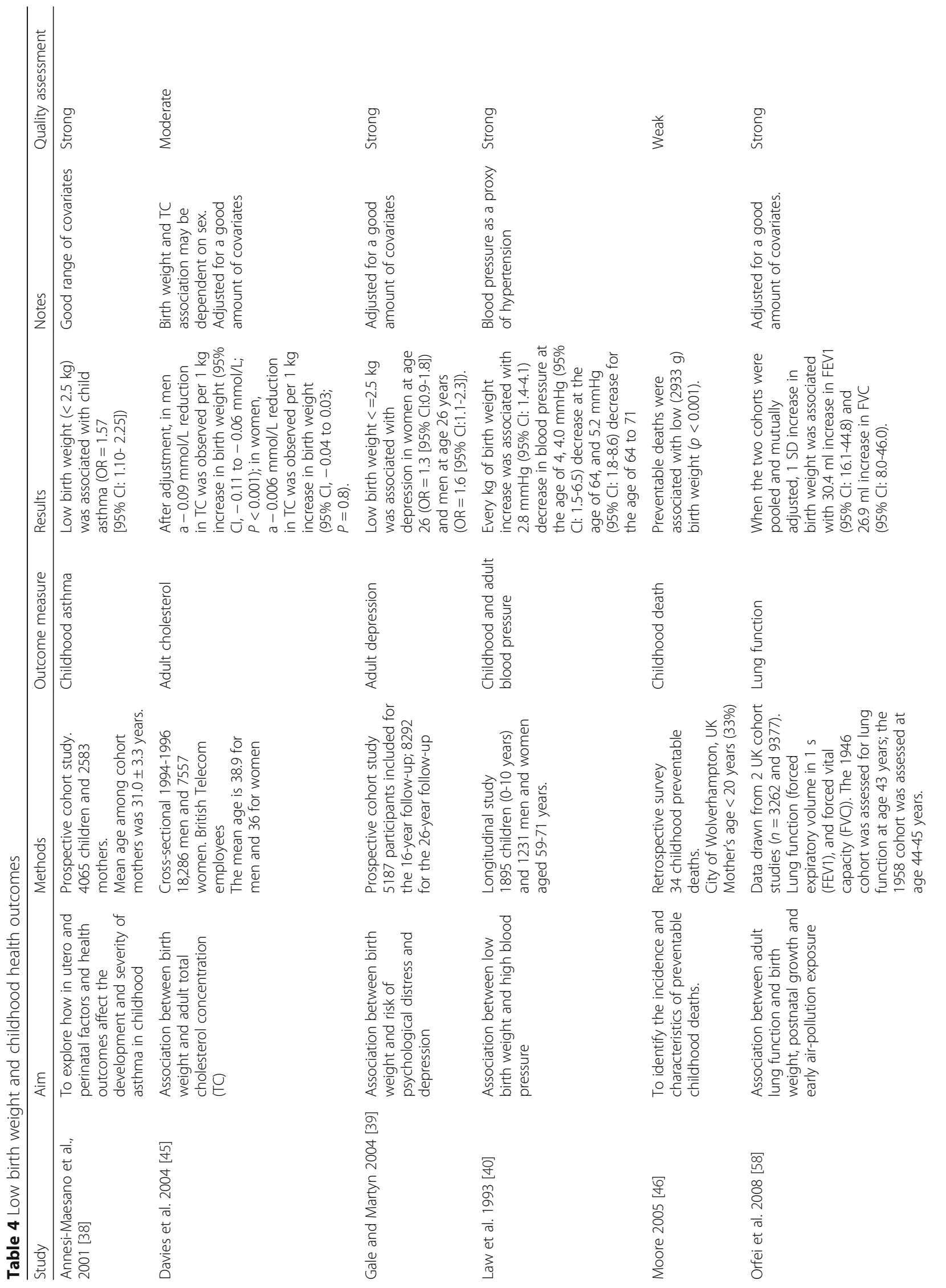




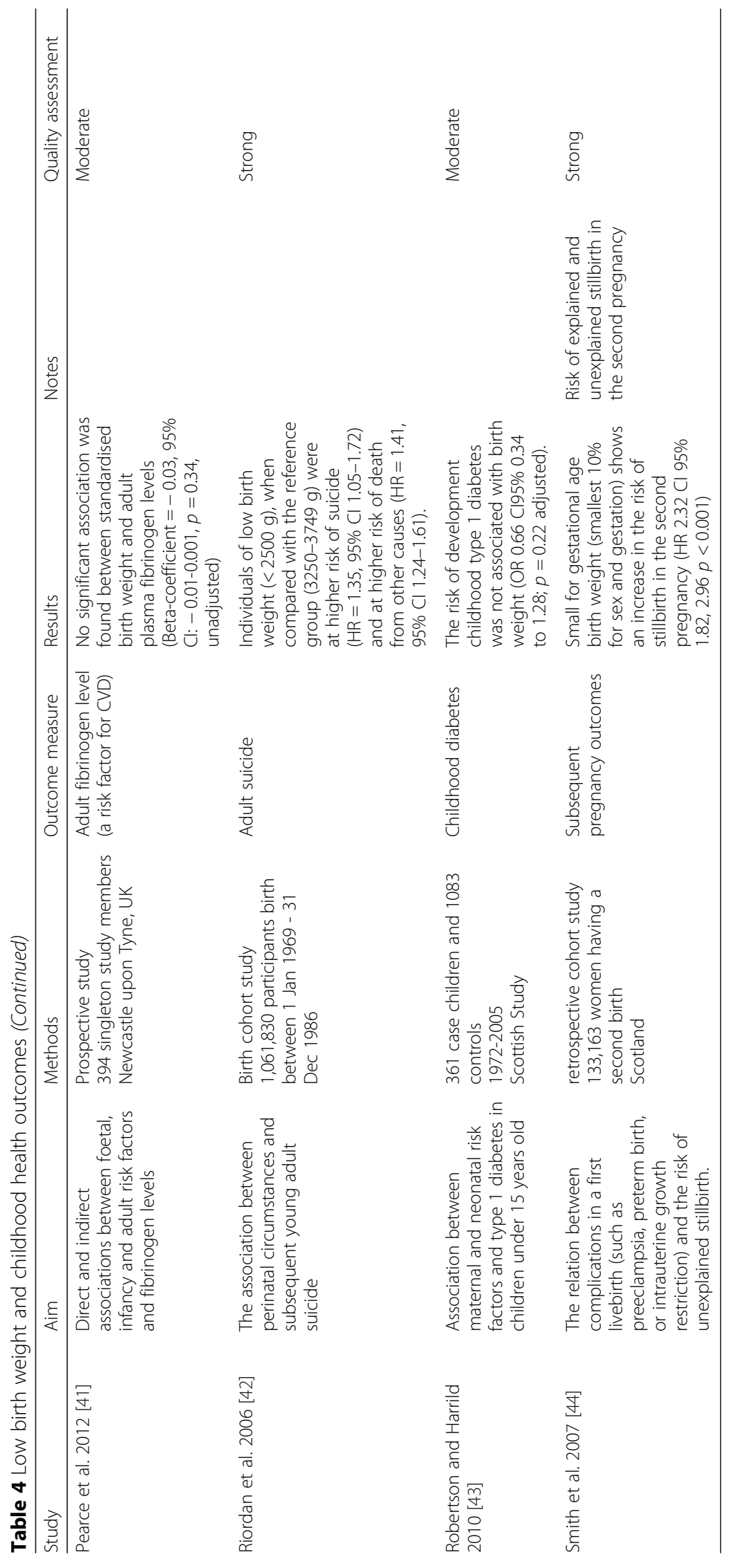




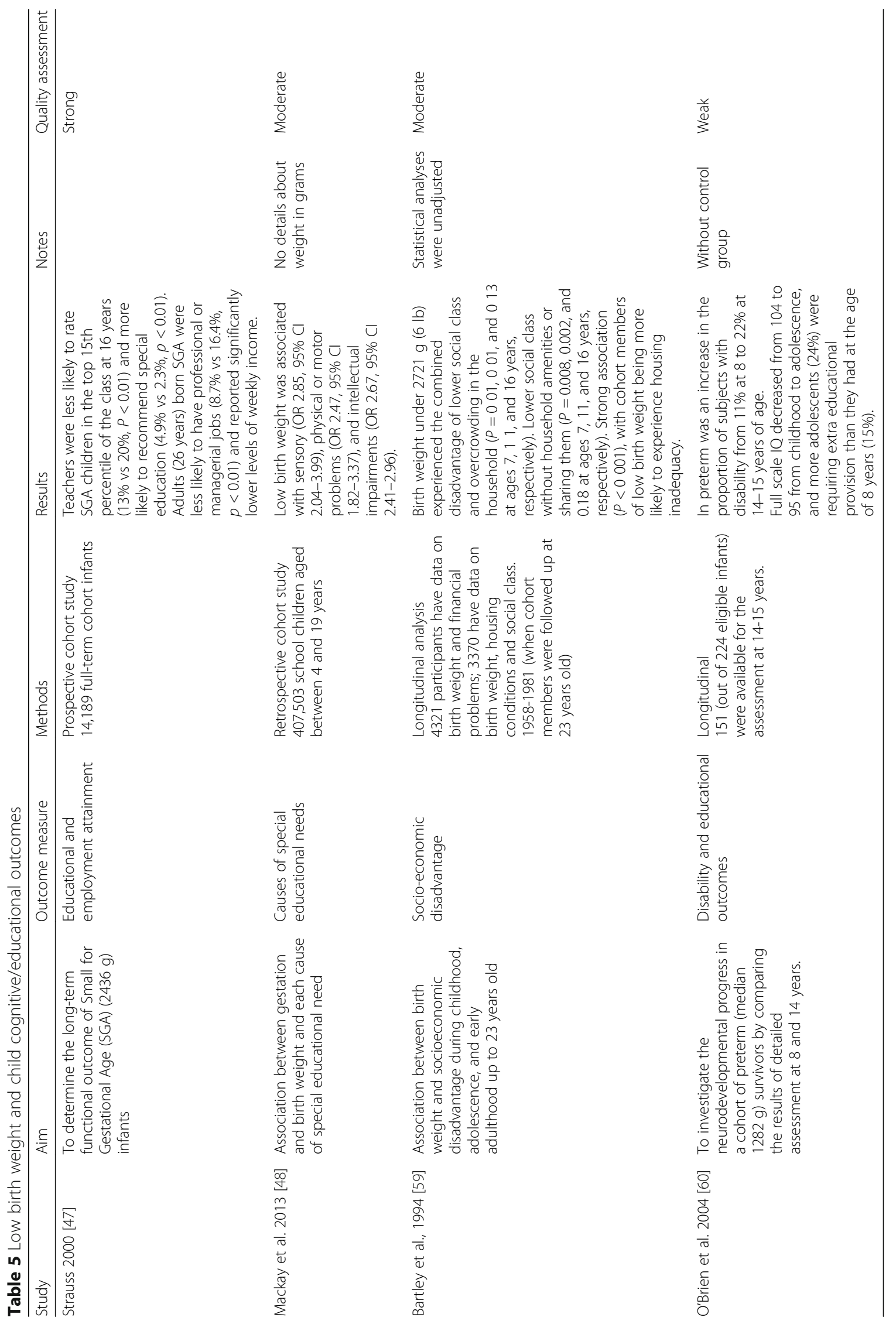




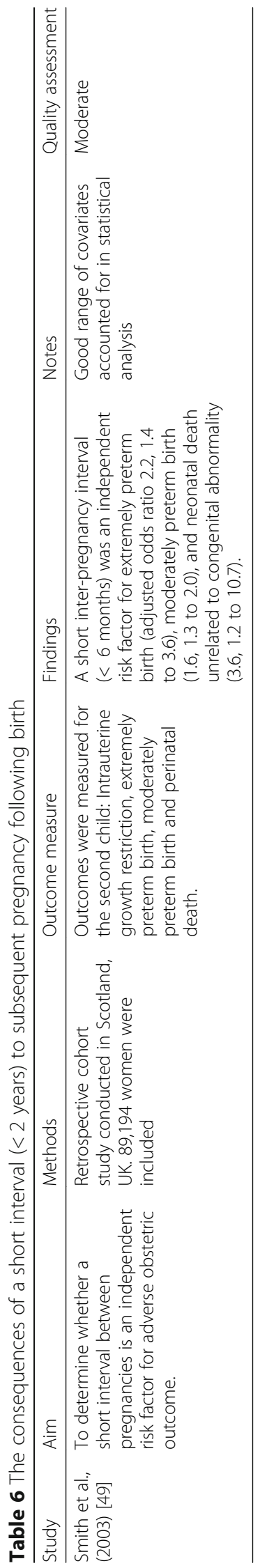


Of the Building Blocks outcomes addressed in the review maternal smoking during pregnancy was most consistently associated with negative child outcomes, particularly health. Weight related problems and child respiratory conditions such as asthma and wheeze were strongly associated with maternal smoking during pregnancy and several other child health outcomes were also highlighted as potential consequences. In terms of societal consequences, one study reported an increased likelihood of convictions for criminal activity associated with children of prenatal smoking mothers [34]. A high cost is associated with criminal activity, particularly that associated with incarceration, with the annual average cost for each prisoner in the UK exceeding $£ 35,000$ [50]. Thus if maternal prenatal smoking is linked to children committing criminal offences in later life, this represents another opportunity for later cost savings associated with a reduction in smoking. The limited UK-based literature available suggests that the potential value of reducing prenatal smoking in mothers on children's educational outcomes is small, with a reduction unlikely to bring about any considerable benefits or cost-savings over the long-term. However, it is important to recognise that this finding is based on only a small number of studies conducted exclusively within a UK context.

Low birth weight was also associated with a vast range of health outcomes such as cardiovascular, respiratory and psychological health. Some potential links with educational attainment were also visible in the literature.

The quality of research entered into a systematic review is directly related to the quality and validity of the results. All included studies were thus assessed for methodological quality using recognised screening criteria [12]. Of the 43 studies included in the review, 41 met the criteria to be considered high or moderate quality, having larger sample sizes, more robust assessment measures and more rigorously conducted statistical analyses controlling for a good range of important potential confounders. Only 2 studies did not meet these criteria. Given that $95 \%$ of included studies were considered good quality, we can assume validity in the review findings.

A systematic review was considered the best methodology to answer the current research question. A rigorous search strategy and distinct inclusion and exclusion criteria were employed which yielded a diverse range of relevant good quality studies. The search strategy itself was derived using expert guidance from a systematic review specialist, to ensure all relevant search terms were covered and all relevant databases were searched, thus we can be confident of its adequacy in addressing the question and retrieving the maximum number of results. Pre-defined inclusion and exclusion ensured a robust study selection procedure, further enhanced by the engagement of two reviewers in the selection process.
Examining outcomes pertaining to aspects beyond the realms of health care, such as educational attainment and criminal activity, is a particular strength of the study providing a more complete picture of the potential longterm outcomes associated with the primary Building Blocks trial outcomes. This allows for potential benefits not only to the health care system but also to other areas of society to be observed.

As no studies exploring the association between childhood A\&E attendances and admissions were identified, this could highlight a potential limitation in the search strategy. Given that A\&E attendances and hospital admissions was considered in the Building Blocks trial to be a proxy for levels of child maltreatment, the inclusion of literature examining the long-term outcomes associated with maltreatment were considered. However, maltreatment is an extremely broad topic and it would not have been feasible to examine the literature within the timeframe of the trial, though has been reviewed elsewhere [51]. Instead, the search aimed to identify studies specifically exploring A\&E attendance and hospital admission related studies. The search also aimed to identify papers relating to the longterm consequences of hospital attendances due to child injury and ingestions, though no studies was identified. This reflects a gap in the UK-based literature.

No studies exploring the association between this outcome measure and later health and development were found. This is not a surprising finding given that studies are more likely to report long-term outcomes based on the cause of A\&E attendances/hospital admissions, rather than focusing on the dichotomy of whether children experienced these attendances or not. It would be impossible to derive a search strategy that could encompass all causes of A\&E attendances/hospital admission and all the long-term consequences. This is thus a limitation of the present review.

For pragmatic reasons, specifically time and capacity, the search strategy was restricted to identify UK-based research only. It is likely that a much larger evidence base exists when the scope is extended beyond the UK, however, this review sought to identify useable evidence to enable modelling of specific short-term outcomes associated with the Building Blocks trial using the most relevant setting of the UK. Had the Building Blocks trial shown a significant effect on prenatal smoking or birthweight, the review would have yielded sufficient information for an extrapolation exercise to be undertaken. Extrapolation would not have been possible for the remaining outcomes, interval to second pregnancy and hospital attendances. Were the effects of the intervention on these outcomes to have been positive, it may have been necessary to consider literature from non-UK sources for extrapolation; however, given that no significant differences were observed for any of the primary outcomes in the trial, this was not required. 
This review highlights a number of areas where large potential benefits could be observed as a consequence of improvements made to the primary outcomes of the Building Blocks trial. For instance a reduction in maternal smoking during pregnancy would likely result in a decrease in the proportion of health problems in their children, as well as bringing about gains in educational attainment and criminal activity.

Taken together, the findings of the systematic review show that if improvements could be made in terms of the primary trial outcomes, real benefits could be observed over the longer-term. The most promising gains lie in childhood and adult health, particularly for respiratory illness and weight management problems. Further potential benefits to educational attainment through improved behaviour and cognitive development were also identified.

\section{Abbreviations}

EPHPP: Effective Public Health Practice Project; FNP Family: Nurse Partnership; HTA: Health Technology Assessment; NICE: The National Institute for Health and Care Excellence; RCT: Randomised controlled trial; SIDS: Sudden Infant Death Syndrome; SRU: Social Research Unit; UK: United Kingdom; US: Unites States of America; WSIPP: Washington State Institute for Public Policy

\section{Acknowledgments}

This is an independent report commissioned and funded by the Policy Research Programme in the Department of Health (reference 006/0060). The views expressed are not necessarily those of the Department of Health. The South East Wales Trials Unit (SEWTU) is funded by the Wales Assembly Government through Health and Care Research Wales and the authors gratefully acknowledge SEWTU's contribution to study implementation. We thank all the women who participated in the study, the local professionals who facilitated recruitment and study implementation, and the family nurses who delivered the intervention. We acknowledge all other contributors to the study who are listed in full in the published full study report. We thank the trial steering committee independent members: Ann Louise Kinmonth (Chair), Silvia van den Heijkant, Pamela Park, Stavros Petrou, Rachel Tonkin; and the data monitoring committee independent members: Gordon Taylor (Chair), Lucy Akhtar, Sara Kenyon. We would like to pay special tribute to the late Professor Paul Wainwright who was the initial Chair of the Data Monitoring Committee. We thank the stakeholder involvement work package members: Joyce Kenkre (lead), Lily Bidmead, Kamila Hawthorne, Lesley Lowes, with contributions from members of the Books \& Babies Group, and the Young Mums Groups. The trial administrators were Jackie Swain, Katy Addison, and Rhys Thomas. The authors also thank Lisa Stirk for her assistance in developing the search strategy and Dr. Lu Han for her assistance with the data extraction.

\section{Funding}

This in an independent research commissioned and funded by the Policy Research Programme in the Department of Health (reference 006/0060). The views expressed are not necessarily those of the Department of Health.

\section{Availability of data and materials}

The dataset supporting the conclusions of this article is available upon request from the corresponding author.

\section{Authors' contributions}

$\mathrm{KB}$ was responsible for the synthesis of extracted data and wrote the first draft of the paper. BC and SR conducted the search and review of articles. GR and DT contributed to the design and methodological approach for the health economics component of the Building Blocks trial. MR is the Chief Investigator for the trial and acts as overall guarantor for the study. All authors read and approved the final manuscript.

\section{Ethics approval and consent to participate}

This work formed part of the Building Blocks Trial. The Building Blocks trial was approved by the Wales NHS Research Ethics Committee (09/MRE09/08) and received governance approval from all participants sited. The trial is registered with International Standard Randomised Control Trial Number ISRCTN23019866.

\section{Consent for publication}

Not applicable

\section{Competing interests}

The authors declare that they have no competing interests.

\section{Publisher's Note}

Springer Nature remains neutral with regard to jurisdictional claims in published maps and institutional affiliations.

\section{Author details}

${ }^{1}$ York Trials Unit, Department of Health Sciences, University of York, ARRC Building, York YO10 5DD, UK. ${ }^{2}$ Centre for Health Economics, University of York, York YO10 5DD, UK. ${ }^{3}$ Centre for Trials Research, Cardiff University, Cardiff CF14 4YS, Wales.

Received: 22 June 2017 Accepted: 11 January 2018

Published online: 24 January 2018

References

1. Sculpher MJ, Claxton K, Drummond M, McCabe C. Whither trial-based economic evaluation for health care decision making? Health Econ. 2006; 15(7):677-87.

2. Claxton $\mathrm{K}$, Sculpher $\mathrm{M}$, Drummond $\mathrm{M}$. A rational framework for decision making by the National Institute for Clinical Excellence (NICE). Lancet. 2002; 360(9334):711-5.

3. Heckman JJ. Skill formation and the economics of investing in disadvantaged children. Science. 2006:312(5782):1900-2.

4. Heckman JJ. The economics, technology, and neuroscience of human capability formation. P Natl Acad Sci USA. 2007;104(33):13250-5.

5. Heckman JJ. Schools, skills, and synapses. Econ Inq. 2008;46(3):289-324.

6. Lee SAS, Drake E, Pennucci A, Miller M, Anderson L. Return on investment: evidence-based options to improve state-wide outcomes, April 2012. Olympia: Washington State Institute for Public Policy; 2012. (Document No. 12-04-1201)

7. Little M, Bjornstad G, Edovald T. Investing in children: an overview. Dartington: Social Research Unit; 2013.

8. Robling M, Bekkers MJ, Bell K, Butler CC, Cannings-John R, Channon S, et al. Effectiveness of a nurse-led intensive home-visitation programme for firsttime teenage mothers (building blocks): a pragmatic randomised controlled trial. Lancet. 2016;387(10014):146-55.

9. Scottish Intercollegiate Guidelines Network (SIGN). 2012. Available from: http://www.sign.ac.uk/search-filters.html.

10. Reeves BC, Deeks JJ, Higgins JPT, Wells GA. Chapter 13: including nonrandomized studies. In: JPT H, Green S, editors. Cochrane handbook for systematic reviews of interventions version 501 [updated September 2008]: The Cochrane Collaboration. Chichester: Wiley; 2008. Available from http://training. cochrane.org/handbook.

11. Deeks JJ, Dinnes J, D'Amico R, Sowden AJ, Sakarovitch C, Song F, et al. Evaluating non-randomised intervention studies. Health technology assessment. Winchester: Health Technology Assessment; 2003. 7(27):iii-x, 1iii-x173.

12. Thomas H. Quality assessment tool for quantitative studies. Effective public health practice project. Toronto: McMaster University. Available from: http:// www.ephpp.ca/tools.html.

13. Henderson AJ, Sherriff A, Northstone K, Kukla L, Hruba D. Pre- and postnatal parental smoking and wheeze in infancy: cross cultural differences. Avon study of parents and children (ALSPAC) study team, European longitudinal study of pregnancy and childhood (ELSPAC) co-ordinating Centre. Eur Respir J. 2001;18(2):323-9.

14. Golding J, Paterson M, Kinlen LJ. Factors associated with childhood cancer in a national cohort study. Br J Cancer. 1990;62(2):304-8. 
15. Ramadas RA, Sadeghnejad A, Karmaus W, Arshad SH, Matthews S, Huebne $M$, et al. Interleukin-1R antagonist gene and pre-natal smoke exposure are associated with childhood asthma. Eur Respir J. 2007;29(3):502-8.

16. Sadeghnejad A, Karmaus W, Arshad SH, Kurukulaaratchy R, Huebner M, Ewart S. IL13 gene polymorphisms modify the effect of exposure to tobacco smoke on persistent wheeze and asthma in childhood, a longitudinal study. Respir Res. 2008;9:2.

17. Strachan DP, Butland BK, Anderson HR. Incidence and prognosis of asthma and wheezing illness from early childhood to age 33 in a national British cohort. BMJ. 1996;312(7040):1195-9.

18. Hawkins SS, Cole TJ, Law C, Millennium Cohort Study Child Health Group. An ecological systems approach to examining risk factors for early childhood overweight: findings from the UK millennium cohort study. J Epidemiol Community Health. 2009;63(2):147-55.

19. Koshy G, Delpisheh A, Brabin BJ. Dose response association of pregnancy cigarette smoke exposure, childhood stature, overweight and obesity. Eur J Pub Health. 2011;21(3):286-91.

20. Power C, Atherton K, Thomas C. Maternal smoking in pregnancy, adult adiposity and other risk factors for cardiovascular disease. Atherosclerosis. 2010;211(2):643-8.

21. Power $\mathrm{C}, \mathrm{BJMH}$ J. Fetal environment and subsequent obesity: a study of maternal smoking. Int J Epidemiol. 2002;31(2):413-9.

22. Power C, Li L, Manor O, Davey SG. Combination of low birth weight and high adult body mass index: at what age is it established and what are its determinants? J Epidemiol Community Health. 2003;57(12):969-73.

23. Thomas C, Hypponen E, Power C. Prenatal exposures and glucose metabolism in adulthood: are effects mediated through birth weight and adiposity? Diabetes Care. 2007;30(4):918-24.

24. Toschke AM, Ehlin A, Koletzko B, Montgomery SM. Paternal smoking is associated with a decreased prevalence of type 1 diabetes mellitus among offspring in two national British birth cohort studies (NCDS and BCS70). J Perinat Med. 2007;35(1):43-7.

25. Toschke AM, AGC E, von Kries R, Ekbom A, Montgomery SM. Maternal smoking during pregnancy and appetite control in offspring. J Perinat Med. 2003;31(3):251-6.

26. Blair PS, Fleming PJ, Bensley D, Smith I, Bacon C, Taylor E, et al. Smoking and the sudden infant death syndrome: results from 1993-5 case-control study for confidential inquiry into stillbirths and deaths in infancy. Confidential enquiry into stillbirths and deaths regional coordinators and researchers. BMJ. 1996;313(7051):195-8.

27. Little J, Cardy A, Arslan MT, Gilmour M, Mossey PA, United Kingdom-based case-control study. Smoking and orofacial clefts: a United Kingdom-based case-control study. Cleft Palate Craniofac J. 2004;41(4):381-6.

28. Larsson M, Montgomery SM. Maternal smoking during pregnancy and physical control and coordination among offspring. J Epidemiol Community Health. 2011;65(12):1151-8

29. Collins BN, Wileyto EP, MFG M, Munafo MR. Adolescent environmental tobacco smoke exposure predicts academic achievement test failure. J Adolesc Health. 2007;41(4):363-70.

30. Brion M-J, Victora C, Matijasevich A, Horta B, Anselmi L, Steer C, et al. Maternal smoking and child psychological problems: disentangling causal and noncausal effects. Pediatrics. 2010;126(1):e57-65.

31. Hutchinson J, Pickett KE, Green J, Wakschlag LS. Smoking in pregnancy and disruptive behaviour in 3-year-old boys and girls: an analysis of the UK millennium cohort study. J Epidemiol Community Health. 2010;64(1):82-8.

32. Maughan B, Taylor A, Caspi A, Moffitt TE. Prenatal smoking and early childhood conduct problems: testing genetic and environmental explanations of the association. Arch Gen Psychiatry. 2004;61(8):836-43.

33. Hay DF, Pawlby S, Waters CS, Perra O, Sharp D. Mothers' antenatal depression and their children's antisocial outcomes. Child Dev. 2010;81(1):149-65.

34. Murray J, Irving B, Farrington DP, Colman I, Bloxsom CAJ. Very early predictors of conduct problems and crime: results from a national cohort study. J Child Psychol Psychiatry. 2010;51(11):1198-207.

35. Fergusson DM, John Horwood L, Ridder EM. Show me the child at seven: the consequences of conduct problems in childhood for psychosocial functioning in adulthood. J Child Psychol Psyc. 2005;46(8):837-49.

36. Klein RG, Mannuzza S, Olazagasti MA, Roizen E, Hutchison JA, Lashua EC, et al. Clinical and functional outcome of childhood attention-deficit/ hyperactivity disorder 33 years later. Arch Gen Psychiatry. 2012;69(12): 1295-303.
37. Murray J, Irving B, Farrington DP, Colman I, Bloxsom CAJ. Very early predictors of conduct problems and crime: results from a national cohort study. J Child Psychol Psyc. 2010;51(11):1198-207.

38. Annesi-Maesano I, Moreau D, Strachan D. In utero and perinatal complications preceding asthma. Allergy. 2001;56(6):491-7.

39. Gale CR, Martyn CN. Birth weight and later risk of depression in a national birth cohort. Br J Psychiatry. 2004;184:28-33.

40. Law CM, de Swiet M, Osmond C, Fayers PM, Barker DJ, Cruddas AM, et al. Initiation of hypertension in utero and its amplification throughout life. BMJ. 1993;306(6869):24-7.

41. Pearce MS, Ahmed A, PWG T, Parker L, Unwin NC. Lifecourse predictors of adult fibrinogen levels: the Newcastle thousand families study. Int J Cardiol. 2012;155(2):206-11.

42. Riordan DV, Selvaraj S, Stark C, JSE G. Perinatal circumstances and risk of offspring suicide - birth cohort study. Br J Psychiatry. 2006;189:502-7.

43. Robertson L, Harrild K. Maternal and neonatal risk factors for childhood type 1 diabetes: a matched case-control study. BMC Public Health. 2010;10:281.

44. GCS S, Shah I, White IR, Pell JP, Dobbie R. Previous preeclampsia, preterm delivery, and delivery of a small for gestational age infant and the risk of unexplained stillbirth in the second pregnancy: a retrospective cohort study, Scotland, 1992-2001. Am J Epidemiol. 2007;165(2):194-202.

45. Davies AA, Smith GD, Ben-Shlomo Y, Litchfield P. Low birth weight is associated with higher adult total cholesterol concentration in men: findings from an occupational cohort of 25,843 employees. Circulation. 2004;110(10):1258-62.

46. Moore A. Changing patterns of childhood mortality in Wolverhampton. Arch Dis Child. 2005;90(7):687-91.

47. Strauss RS. Adult functional outcome of those born small for gestational age - twenty-six-year follow-up of the 1970 British birth cohort. JAMA. 2000; 283(5):625-32

48. Mackay DF, GCS S, Dobbie R, Cooper SA, Pell JP. Obstetric factors and different causes of special educational need: retrospective cohort study of 407503 schoolchildren. Bjog-an international. J Obstet Gynaecol. 2013; 120(3):297-308

49. Smith GCS, Pell JP, Dobbie R. Interpregnancy interval and risk of preterm birth and neonatal death: retrospective cohort study. BMJ. 2003;327(7410):313.

50. Ministry of Justice. Costs per place and costs per prisoner by individual establishment 2015 to 2016 tables. London: Ministry of Justice; 2016.

51. Norman RE, Byambaa M, De R, Butchart A, Scott J, Vos T. The long-term health consequences of child physical abuse, emotional abuse, and neglect: a systematic review and meta-analysis. PLoS Med. 2012;9(11):e1001349.

52. Fertig AR. Selection and the effect of prenatal smoking. Health Econ. 2010; 19(2):209-26.

53. Pang D, McNally R, Birch JM. Parental smoking and childhood cancer: results from the United Kingdom childhood cancer study. Br J Cancer. 2003:88(3):373-81.

54. Severson RK, Buckley JD, Woods WG, Benjamin D, Robison LL. Cigarette smoking and alcohol consumption by parents of children with acute myeloid leukemia: an analysis within morphological subgroups-a report from the Childrens cancer group. Cancer Epidemiol Biomark Prev. 1993;2(5):433-9.

55. Sorahan T, Lancashire R, Prior P, Peck I, Stewart A. Childhood cancer and parental use of alcohol and tobacco. Ann Epidemiol. 1995;5(5):354-9.

56. Sorahan T, Lancashire RJ. Parental cigarette smoking and childhood risks of hepatoblastoma: OSCC data. Br J Cancer. 2004;90(5):1016-8.

57. Macleod J, Hickman M, Bowen E, Alati R, Tilling K, Smith GD. Parental drug use, early adversities, later childhood problems and children's use of tobacco and alcohol at age 10: birth cohort study.[erratum appears in addiction. 2008 Dec;103(12):2075]. Addiction. 2008;103(10):1731-43.

58. Orfei $L$, Strachan DP, Rudnicka AR, MEJ W. Early influences on adult lung function in two national British cohorts. Arch Dis Child. 2008;93(7):570-4.

59. Bartley M, Power C, Blane D, Smith GD, Shipley M. Birth weight and later socioeconomic disadvantage: evidence from the 1958 British cohort study. BMJ. 1994;309(6967):1475-8.

60. O'Brien F, Roth S, Stewart A, Rifkin L, Rushe T, Wyatt J, et al. Arch Dis Child. 2004;89(3):207-11. 